\title{
Chemsex among HIV-infected patients - experience from a tertiary care hospital in Poland. Preliminary data
}

\author{
Anna W. Bartnik, Dagny Krankowska², Mariusz Sapuła², Aneta Cybula², Alicja Wiercińska-Drapało² \\ ${ }^{1}$ Students' Science Society of the Department of Infectious and Tropical Diseases and Hepatology, Medical University of Warsaw, Poland \\ ${ }^{2}$ Department of Infectious and Tropical Diseases and Hepatology, Medical University of Warsaw, Poland
}

\begin{abstract}
Introduction: Chemsex describes the growing phenomenon of intentional usage of psychoactive substances before or during sex. There are concerns that this practice is increasing in popularity among men who have sex with men (MSM), especially those living with human immunodeficiency virus (HIV), and that it might lead to an increase in sexually transmitted infections (STIs). The aim of this study was to assess the prevalence of chemsex among patients with HIV, treated at a tertiary care department in Warsaw, Poland.

Material and methods: The study enrolled 50 patients with HIV treated in a tertiary care facility in Poland. All subjects underwent a survey including 21 questions focusing on drug usage, number of sexual contacts after drugs, and the presence of STIs. The survey was carried out by the Department of Infectious and Tropical Diseases and Hepatology, the Medical University of Warsaw. The data was collected between the $10^{\text {th }}$ of January and the $10^{\text {th }}$ of April 2019. This article presents preliminary data.

Results: The study included 50 men, with median age 39.5 years (27-71). Out of the 50 patients 31 (62\%) who responded to the questionnaire were MSM, 24 patients (48\%) declared participating in chemsex, and $50 \%$ of this group (12/24) have had unprotected sex during chemsex. Of the drug users $37.5 \%(9 / 24)$ had acquired an STI other than HIV.

Conclusions: Our study showed that chemsex is a rising problem even among regularly monitored patients. The fact that $48 \%$ of patients participating in the study admitted to participating in chemsex shows that more attention should be drawn to this subject, with special attention towards MSM. Questions about drug usage and chemsex should be part of physicians' every day care of patients with HIV in order to prevent morbidities associated with drug intake.
\end{abstract}

HIV AIDS Rev 2019; 18, 2: 137-141

DOI: https://doi.org/10.5114/hivar.2019.86378

Key words: HIV, psychoactive substances, chemsex, sexually transmitted infections.

\section{Introduction}

"Chemsex" describes a phenomenon increasing in popularity, which is intentional drug usage before or during sex to facilitate and enhance sexual contact $[1,2]$. It is main-

ly described among men who have sex with men (MSM). The main drugs used are mephedrone, $\gamma$-hydroxybutyrate/ $\gamma$-butyrolactone (GHB/GBL), and methamphetamine; however, polydrug usage is also reported. Usage of drugs such as alkyl/butyl nitrates (poppers), MDMA (ecstasy), cocaine,

Article history:

Received: 26.04.2019

Received in revised form: 07.06.2019

Accepted: 07.06.2019

Available online: 23.06.2019
International Journal of HIV-Related Problem

HIV \& AIDS

R e vi e w 
and ketamine have also been described in this context [1-4]. The methods of intake vary from oral, through nasal, to intravenous. Intravenous intake of drugs for the purpose of prolonged sex is called "slamming" [2].

The scale of the problem is not fully known [5]. Some data from a British cohort from 2014 showed that from 1142 MSM who participated in the study, about $20 \%$ reported having chemsex within the past five years [1]. Studies have shown that even people with higher educational status and those who are "out" about their sexuality were involved in chemsex [3].

The motivations for chemsex are many, such as increasing libido and confidence, but also managing negative feelings such as lack of self-esteem, internalised homophobia, and stigma about sexual orientation or HIV status $[1,4]$.

The growth in popularity of chemsex may be related to geosocial networking applications, which are used to participate in "chemsex sessions". It is reported that MSM who use these applications are more educated, younger, and are more likely to undertake risky sexual behaviours under the influence of psychoactive substances than those who do not use such applications [6].

The aim of this study was to assess the prevalence of chemsex among male patients with HIV who are receiving antiretroviral therapy at a tertiary care hospital in Warsaw, Poland. Furthermore, the aim was to assess the occurrence of chemsex-related issues regarding drug usage or STIs. The article presents preliminary data, due to the ongoing collection of data.

\section{Material and methods}

The study recruited 50 consecutive patients with HIV, who were receiving antiretroviral therapy in the Department of Infectious and Tropical Diseases and Hepatology in Warsaw, Poland. Between $10^{\text {th }}$ January and $10^{\text {th }}$ April 2019 the subjects underwent an anonymous questionnaire with 21 questions. Data about demographics (age, origin), socioeconomic factors (education), knowledge of the term "chemsex", drug use (kinds, frequency, and method of administration), sexual behaviours (number of partners, condom use), and sexually transmitted infections (STIs) after drug use was collected.

\section{Results}

We analysed the data of 50 patients. All were men between 27 and 71 years of age (the median age was 39.5 years). The majority of our patients were MSM (31/50, 60\%).

Demographic data and characteristics of the analysed population are presented in Table 1.

The term "chemsex" was familiar to 35 patients $(35 / 50$, $70 \%)$. More than half of the patients in the study group $(29 / 50,58 \%)$ admitted that people from their environment had sex after psychoactive drug intake. Also, almost half of the study group $(24 / 50,48 \%)$ asserted having had chemsex, but only half of them $(12 / 24)$ knew they were representing a phenomenon called "chemsex". 52\% (16/31) of those questioned from MSM had chemsex, while $45 \%$ of nonMSM (5/11) had chemsex. The sexual preferences of eight patients regarding their partner's gender were unknown, and three of those patients had chemsex.

Among the chemsex users, half of the patients (12/24, $50 \%$ ) admitted to having unprotected sex during chemsex sessions. Also, half of the chemsex users $(12 / 24,50 \%)$ admitted that they might have acquired HIV through sexual contacts after psychoactive drug usage in the past.

Of the chemsex group, $3 / 24$ (12.5\%) patients admitted to having sex after psychoactive drug intake more than five times per month. Two of the patients affirming having

Table 1. Characteristics of the study population

\begin{tabular}{l|c|c|c|c|c}
\hline & \multicolumn{2}{|c|}{ Min. } & \multicolumn{2}{c}{ Max. } & \multicolumn{2}{c}{ Median } \\
\hline Age & \multicolumn{2}{|c|}{21} & 71 & Town $100,000-500,000$ & Town $>500,000$ \\
\hline Town & Countryside & Town $<50,000$ & Town 50,000-100,000 & $1(2 \%)$ & $38(76 \%)$ \\
\hline No. of patients & $2(4 \%)$ & $7(14 \%)$ & $2(4 \%)$ & High school & University \\
\hline Education & None & Secondary & Professional technical school & $6(12 \%)$ & $33(66 \%)$ \\
\hline No. of patients & 0 & $5(10 \%)$ & $6(12 \%)$ & &
\end{tabular}

Table 2. Data about chemsex users presented as numbers of patients who answered "Yes" or "No", or did not respond to the questions in the study

\begin{tabular}{|c|c|c|c|}
\hline Question & Yes & No & Lack of data \\
\hline Did you use psychoactive substances directly before or during intercourse? & 24 & 26 & \\
\hline Do you use condoms during sexual intercourse after the intake of psychoactive substances? & 12 & 11 & 1 \\
\hline $\begin{array}{l}\text { Is it possible that you became infected with HIV during intercourse after psychoactive } \\
\text { substance intake? }\end{array}$ & 12 & 11 & 1 \\
\hline
\end{tabular}


Table 3. Data about chemsex: frequency of chemsex sessions per month and maximal number of sexual partners during chemsex

\begin{tabular}{l|c|c|c|c|c}
\hline Question & $\mathbf{1}$ & $\mathbf{2 - 3}$ & $\mathbf{4 - 5}$ & $\mathbf{> 5}$ & Lack of data \\
\hline How often do you use psychoactive substances before or during sexual contact? & 12 & 7 & 0 & 3 & 2 \\
\hline What is the largest number of sexual partners you have had during one "chemsex" session? & 11 & 8 & 2 & 2 & 1 \\
\hline
\end{tabular}

Table 4. Data about psychoactive substances used during chemsex

\begin{tabular}{l|c|c|c|c|c|c|c|c|c}
\hline $\begin{array}{l}\text { Psychoactive } \\
\text { substance }\end{array}$ & Amphetamine & Mephedrone & Cocaine & $\begin{array}{c}\text { Alkyl/butyl } \\
\text { nitrates } \\
\text { (poppers) }\end{array}$ & $\begin{array}{c}\text { MDMA } \\
\text { (ecstasy) }\end{array}$ & GBL/GHB & Heroin & $\begin{array}{c}\text { Designer } \\
\text { drugs }\end{array}$ & Marihuana \\
\hline $\begin{array}{l}\text { Number } \\
\text { of patients }\end{array}$ & 9 & 9 & 4 & 3 & 2 & 2 & 2 & 1 & 10 \\
\hline
\end{tabular}

chemsex $(2 / 24,8.3 \%)$ have had more than five sexual partners per chemsex session (Table 3 ).

The spectrum of substances used per chemsex session asserted by patients was very wide. The most commonly used drugs were amphetamine, mephedrone, and cocaine. Patients also listed other substances: alkyl/butyl nitrates (poppers), MDMA (ecstasy), GBL ( $\gamma$-Butyrolactone), and others. 6/24 (25\%) of drug users had used two drugs or more per "chemsex" session (Table 4).

Nasal administration (snorting) of drugs was the most popular route of drug intake in our study (15/24, 62.5\%). The second most popular was smoking (10/24, 42.0\%). Two of our patients $(2 / 24,8.3 \%)$ had used drugs intravenously during chemsex. Another two patients had used drugs intravenously in the past.

Most of the patients who had had sexual contact under the influence of psychoactive substances said that they did it at home $(23,96 \%$ patients $)$ and/or at a night club $(9,37.5 \%$ patients).

Known cases of sexually transmitted infections occurred in 9 out of 24 (37.5\%) of our patients who had had chemsex. The most frequently acquired STI was syphilis (6/24 cases, $25 \%)$. Patients additionally admitted to the Clinic due to: genital warts $(1 / 24,4.2 \%)$, gonorrhoea (one case of coinfection with syphilis), chlamydia (one case of coinfection with syphilis), CMV infection (1/24, 4.2\%), and HCV infection $(1 / 24,4.2 \%)$. Participants of this study during regular medical visits are not screened for asymptomatic STI infections of gonorrhoea or chlamydia.

\section{Discussion}

The routes of transmission of HIV vary between countries. In the majority of European Union countries, the main route of transmission of HIV is between men having sex with men. Even though intravenous drug use has decreased, the new public health issue might be the oral and nasal usage of drugs, especially when used for chemsex. The chemsex phenomenon concerns mostly MSM [1, 6-8]. A few studies show that MSM use recreational drugs (not only for chem- sex) more often than the general population $[3,8]$. Within the last few years data from several sexual health clinics have shown an increase in drug use for chemsex by MSM [9]. We have a similar observation from our study - the majority of drug users and patients participating in chemsex were MSM (16/24), but our group is small and more data need to be gathered. This raises a question about the motivation for drug usage in this specific group. Some studies show that syndemic conditions such as depression, substance use, and sexual stigma might increase the risk of undertaking risky sexual behaviours among MSM [9].

In our questionnaire there were no questions about depression - a further study of this health issue is required.

Another growing problem is polydrug use during sexual contact. Polydrug usage is usually described as using three or more drugs during a single session. In our study $25 \%$ of those who admitted to having chemsex had used more than two drugs, with two patients using more than five substances per chemsex session. We found similar results in the literature, where usually about $22 \%$ of analysed patients participating in chemsex admitted to polydrug use $[3,10,11]$.

Chemsex might have a variety of health consequences, starting from addictions (psychological and physical), mental health problems (depression and/or psychosis), STIs, and interactions between drugs and antiretroviral medicine as well as loss of consciousness. The latter might become an obstacle to proper drug adherence or for HIV-negative patients - missing the opportunity for the post-exposure prophylaxis [14]. Data from a British LGBT (lesbian, gay, bisexuals, and transgender) charity drug and alcohol service (Antidote) show that participants in chemsex have an average of five sexual partners per session and that unprotected sex is the norm $[12,13]$. In our study $50 \%$ of chemsex users admitted to having more than one sexual partner during a session (two had had more than five partners). Half (12/24, 50\%) of chemsex participants in our study did not use condoms. Therefore, it is not surprising that many of those patients had STIs. In our study almost $40 \%$ of patients participating in chemsex had acquired an STI $(9 / 24,37.5 \%)$. Similar data is reported by Sewell et al. - the authors state that there has 
been an increase in the number of self-reported bacterial STI diagnoses in HIV-negative MSM. Interestingly Sewell et al. are citing data from two London clinics that show a decline in HIV diagnoses despite an increase in HIV testing [8]. This phenomenon might be explained by the popularity of pre-exposure prophylaxis (PrEP) used in the UK.

Having multiple partners might also increase the number of patients acquiring the hepatitis A virus and hepatitis $\mathrm{C}$ virus (HAV, HCV). Every few years we notice epidemics of HAV in developed countries. The last one in Europe occurred between 2016 and 2018. According to the European Centre for Disease Prevention and Control, between $1^{\text {st }}$ June 2016 and $7^{\text {th }}$ September 2018, in 22 EU/EEA countries (Poland not included) there were 4475 confirmed cases of HAV. According to the epidemiological data, MSM were those most affected by this disease, with a male-to-female ratio between 6.8 and 11.8 depending on the period of the epidemic [14].

In Poland between $1^{\text {st }}$ January 2017 and $31^{\text {st }}$ December 2017 there were 3072 confirmed cases of HAV whilst in previous years there were around 35-49 cases [15]. We did not ask the participants of our study whether they have had hepatitis $\mathrm{A}$, but we do have some knowledge that some of them were previously admitted to the hospital with HAV infection. Because of the anonymity of the questionnaire we could not analyse this information in the study.

Fernandez-Davila et al. as well as Ingiliz et al. reported an increase in HCV reinfection among MSM $[16,17]$. In our study one patient acquired HCV in the past, and it was due to intravenous drug use not related to chemsex.

Several countries (the United Kingdom, Germany, Spain, Australia, Canada, and the United States) have reported an increase of the incidence of shigellosis in MSM who have not travelled to high-incidence countries [18]. The increase in numbers of shigellosis (in the UK mainly Shigella flexneri $2 \mathrm{a}$ and $2 \mathrm{~b}$ and S. sonnei) among MSM is said to be via the sexual route, mainly the faecal-oral route. None of our patients reported to have acquired Shigella, but it was not mentioned in the questionnaire and usually it is not considered a sexually transmitted disease by patients.

Lastly, an important issue to consider is the influence of the environment on the individual patient. Out of 50 patients $84 \%$ answered the question of whether people from their environment take drugs before sex, and 29 out of them answered yes. Questions then arise: is the topic of "chemsex" still a taboo about which patients do not want to talk with their physicians? Or maybe it is rather that some of the participants of the questionnaire were not familiar with the term chemsex and skipped some questions.

\section{Limitations}

Our study group had only 50 patients, and not all of them responded to all of the questions in the questionnaire. More patients are needed to analyse the data statistically. We are still collecting the questionnaires from other patients.
Another limitation of our study is that we did not ask our patients about PrEP, nor about the influence of chemsex on their antiretroviral adherence. Furthermore, it is important to gain more information about the motivations for chemsex and to ask about mood disorders among our patients.

\section{Conclusions}

Our study, although so far carried out only on a small group, has shown that chemsex among patients with HIV receiving antiretroviral treatment in a tertiary care hospital in Warsaw, Poland is an issue that needs to be addressed.

In these times of quick access to sexual partners and drugs via telephone applications, and in the times of PrEP, it is crucial to intensify educational programs about sexual health. Physicians should promote vaccination programmes (e.g. against HAV) and screening for STIs. Questions about drug usage and chemsex should be part of physicians' everyday care of patients with HIV in order to prevent STIs and other morbidities associated with drug intake. Strong cooperation between infectious disease doctors and psychiatrists would be a great way to help, in a multidisciplinary way, MSM participating in chemsex.

\section{Conflict of interest}

The authors declare no potential conflicts of interest with respect to the research, authorship, and/or publication of this article.

\section{References}

1. McCall H, Adams N, Mason D. What is chemsex and why does it matter? BMJ 2015; 351: h5790.

2. Dolengevich-Segal H, Rodriguez-Salgado B, Ballesteros-Lopez J, Molina-Prado R. Chemsex. An emergent phenomenon. Adicciones 2017; 29: 207-209.

3. Rosińska M, Gios L, Nostlinger C, et al. Network, Prevalence of drug use during sex amongst MSM in Europe: results from a multi-site bio-behavioural survey. Int J Drug Policy 2018; 55: 231-241.

4. Weatherburn P, Hickson F, Reid D, et al. Motivations and values associated with combining sex and illicit drugs ('chemsex') among gay men in South London: findings from a qualitative study. Sex Transm Infect 2017; 93: 203-206.

5. Giorgetti R, Tagliabracci A, Schifano F, et al. When „Chems” meet sex: a rising phenomenon called „chemsex”. Curr Neuropharmacol 2017; 15: 762-770.

6. Zou H, Fan S. Characteristics of men who have sex with men who use smartphone geosocial networking applications and implications for HIV interventions: a systemic review and meta-analysis. Arch Sex Behav 2017; 46: 885-894.

7. Van Hout MC, Crowley D, O'Dea S, Clarke S. Chasing the rainbow: pleasure, sex-based sociality and consumerism in navigating and exiting the Irish Chemsex scene. Cult Health Sex 2019; 2: 1-13.

8. Sewell J, Cambiano V, Miltz A, et al. Changes in recreational drug use, drug use associated with chemsex, and HIV-related behaviours, among HIV-negative men who have sex with men in London and Brighton, 2013-2016. Sex Transm Infect 2018; 94: 494-501.

9. Santos GM, Do T, Beck J, et al. Syndemic conditions associated with increased HIV risk in a global sample of men who have sex with men. Sex Transm Infect 2014; 90: 250-253. 
10. Maxwell S, Shahmanesh M, Gafos M. Chemsex behaviours among men who have sex with men: A systematic review of the literature. Int J Drug Policy 2019; 63: 74-89.

11. Sewell J, Miltz A, Lampe FC, et al. Poly drug use, chemsex drug use, and associations with sexual risk behaviour in HIV-negative men who have sex with men attending sexual health clinics. Int J Drug Policy 2017; 43: 33-43.

12. Bourne A, Reid D, Hickson F, et al. Chemsex and harm reduction need among gay men in South London. Int J Drug Policy 0215; 26 : 1171-1176.

13. London Friend. Antidote. Out of your mind. 2014. Available at: http://londonfriend.org.uk/wp-content/uploads/2014/06/Out-ofyour-mind.pdf (Accessed: 30.03.2019).

14. European Centre for Disease Prevention and Control, Epidemiological update: Hepatitis A outbreak in the EU/EEA mostly affecting men who have sex with men. Available at: https://ecdc. europa.eu/en/news-events/epidemiological-update-hepatitis-outbreak-eueea-mostly-affecting-men-who-have-sex-men-2 (Accessed: 30.03.2019).

15. Zakład Epidemiologii NIZP-PZH, Departament Zapobiegania oraz Zwalczania Zakażeń i Chorób Zakaźnych u Ludzi GIS. Zachorowania na wybrane choroby zakaźne w Polsce od 1 stycznia do 31 grudnia 2017 r. Available at: http://wwwold.pzh.gov.pl/oldpage/ epimeld/2017/INF_17_12B.pdf (Accessed: 30.03.2019).

16. Fernandez-Davila P. "Sesion de sexo, morbo y vicio": una aproximacion holistica para entender la aparicion del fenomeno ChemSex entre hombres gais, bisexuales y otros hombres que tienen sexo con hombres en Espana. Revista Multidisciplinar del Sida 2016; 4 41-65.

17. Ingiliz P, Martin TC, Rodger A, et al. and the NEAT study group Hepatitis $C$ virus reinfection incidence and outcomes among HIVpostitive MSM in western Europe. International Liver Congress, Abstract PS006. Barcelona 2016.

18. Simms I, Field N, Jenkins C, et al. Intensified shigellosis epidemic associated with sexual transmission in men who have sex with men - Shigella flexneri and S. sonnei in England, 2004 to end of February 2015. Euro Surveill 2015; 20: 21097. 